\title{
RANCANG BANGUN ALAT PENGISIAN MINUMAN DAN MONITORING AIR GALON BERBASIS IOT (INTERNET OF THINGS)
}

\author{
Muhammad Dwi Arniyanto, Joseph Dedy Irawan, Febriana Santi Wahyuni \\ Program Studi Teknik Informatika S1, Fakultas Teknologi Industri \\ Institut Teknologi Nasional Malang, Jalan Raya Karanglo km 2 Malang, Indonesia \\ mdwiarniyanto@gmail.com
}

\begin{abstract}
ABSTRAK
Perkembangan teknologi saat ini mempermudah dalam melakukan monitoring pada air galon ketika mau habis. Dalam penelitian ini bertujuan untuk merancang suatu alat yang dapat memonitoring tingkat ketinggian pada galon yang di pakai. Alat yang di buat ini sebagai alternative bagi seseorang untuk mempermudah monitoring air galon di gedung, hotel dan tempat ibadah agar stok air minum di tempat tersebut tetap ada dan lebih efisien terhadap waktu. Sensor Ultrasonic merupakan sebuah sensor yang dapat mengukur ketinggian atau jarak suatu bidang dengan cara di tembakkan ke objeknya. Pada Buzzer digunakan untuk alarm ketika galon habis dan pada led RGB warna merah menunjukkan level low, biru sebagai medium dan warna hijau full. Penggunaan NodeMCU ini sebagai sarana untuk penghubung antara sensor ultrasonic dengan notifikasi telegram dan website monitoring sebagai sarana untuk mengecek status level berapa persen. Berdasarkan hasil pengujian pada notifikasi unit 1, unit 2 dan unit 3 dapat memudahkan untuk melakukan pengawasan melalui telegram. Memudahkan Melakukan Monitoring Menggunakan Website Air Galon pada Unit 1, Unit 2 Dan Unit 3 Agar dapat di control tingkat ketinggian air galon dan dijalankan dengan baik pada browser web dan alat ini dapat di tujukan pada fasilitas seperti hotel, perkantoran dan tempat ibadah. Alat ini dapat bekerja dengan baik, dapat dilihat dari alat yang digunakan seperti notifikasi telegram dan website monitoring di lakukan secara real time agar dapat di pantau terus sehinggan memudahkan dalam pengawasan ketika air galon habis.
\end{abstract}

\section{Kata Kunci : Internet Of Things, Ultrasonic, NodeMCU, Monitoring}

\section{PENDAHULUAN}

Perkembangan teknologi saat ini memberikan suatu kemudahan untuk melakukan segala sesuatu dengan sangat mudah. Salah satu perkembangan era teknologi saat ini adalah pada bidang komunikasi dan informasi. Pada dasarnya di era sekarang ini dituntut untuk mempermudah dalam melakukan pengawasan air galon ketika sudah habis.

Pada penelitian ini bertujuan untuk merancang suatu alat yang dapat memonitoring tingkat ketingguan air pada galon yang di gunakan. Dalam membuat monitorng air galon menggunakan Sensor Ultrasonic dan dilakukan uji kelayakan alat itu sendiri. Alat yang di buat ini sebagai alternative bagi pengguna untuk mempermudah monitoring air galon di gedung, hotel dan tempat ibadah agar stok air minum di tempat tersebut tetap ada dan lebih efisien terhadap waktu.

Saat ini membutuhkan system yang memudahkan pekerjaan manusia sebab di masa sekarang ini membutuhkan suatu kegiatan dengan semudah mungkin seperti pada monitoring air galon ini bisa melakukan pengawasan terhadap isi dari air galon tersebut agar dapat mengontrol tingkat level air galon ketika sudah habis. Monitoring digunakan pada layar gedung atau perkantoran untuk ketersediaan air minum di gedung atau perkantoran. Penggunaan Sensor ultrasonic, akan mengirimkan gelombang yang berupa nilai pada program yang digunakan di Arduino dan melakukan tranver data dengan menggunakan bantuan ESP8266 ke website. Sensor atau ultrasonic sebagai otak dari sistem kendali ini dan dikirimkan dengan bantuan ESP8266 NODE MCU V3. (Bere, 2021)

Melihat di zaman sekarang sudah berkembang pesat dengan adanya teknologi, dan sekarang apapun pekerjaan manusia dapat digantikan oleh mesin. Semuanya bisa dilakukan dengan singkat karena hampir semua sudah di permudah oleh teknologi yang berbasis Iot. IoT atau kepanjangan dari Internet of Things memiliki beberapa manfaat seperti mempermudah pada sistem monitoring air galon misalnya dalam mengontrol level air galon, dengan ini hal itu dapat menerapkan peran IoT dan ini juga penting bagi manusia karena dapat memudahkan kita dalam bekerja dan mengontrol sesuatu dengan baik

\section{TINJAUAN PUSTAKA}

\subsection{Penelitian Terdahulu}

Menurut penelitian Dewanto dkk pada penelitian dengan judul "Tandon Air Otomatis Dengan Sistem Monitoring Melalui Android Berbasis Arduino uno". Tujuan penelitian ini yaitu dalam proses sebagai system monitoring. sistem ini dapat memonitoring pada tandon air menggunakan sensor ultrasonic untuk mendeteksi jarak ketinggian air ketika mau di isi atau sudah penuh. Proses ini dapat monitoring dan dilihat pada android yang di hubungkan menggunakan modul bluetooth. (Dewanto, 2018)

Menurut penelitian Anggara dkk pada penelitian selanjutnya dengan judul "Rancang Bangun Sistem 
Pengatur Pengisian Air Galon Otomatis Berbasis Mikrokontroler Atmega328P”. Tujuan penelitian ini adalah untuk system pengisian air gallon yang pada umumnya sudah modern tetapi pingisianya masih menggunakan manual. oleh karena itu di buatlah system pengisian air gallon yang berbasis otomatis dengan menggunakan sensor ultrasonic sebagai jarak untuk menentukan jarak air pada sensor ultrasonic. (Anggara, 2018)

Menurut penelitian Bere dkk pada penelitian selanjutnya dengan judul "Rancang Bangun Alat Pembuka Dan Penutup Tong Sampah Otomatis Menggunakan Sensor Jarak Berbasis Arduino". Tujuan penelitian ini adalah untuk mempermudah Ketika sedang membuang sampah. Dari hasil penelitian ini jika terdapat orang yang sudah dekat maka tong sampah akan terbuka secara otomatis. jika kotak sampah sudah penuh maka sensor ultrasonic mengirimkan notifikasi kepada telegram. (Bere, 2021)

Menurut penelitian Putra dkk pada Penelitian ini adalah Memonitoring kolam renang agar bisa mengontrol tingkat kekeruhan kolam. System ini dilakukan dengann otomatis menggunakan sensor $\mathrm{pH}$, Keruh Dan Suhu dan di tampilkan pda website secara realtime. (Putra, 2018)

Menurut penelitian Wigino dkk pada penelitian selanjutnya dengan judul "Monitoring Dan Pengisian Air Tandon Otomatis Berbasis Arduino". Tujuan penelitian adalah Merancang system monitoring tandon air. Pada warna merah dapat mengetahui keadaan level air Ketika kosong, warna kuning dapat mengetahui ketinggian air di 30\%, sedangkan warna tosca dapat mengetahui ketinggian air di 50\%, warna ungu dapat mengetahui ketinggian air di $80 \%$ dann warna hijau dapat mengetahui ketinggian air full dengan cara menggunakan sensor ultrasonic. (Wigino, 2018)

Menurut penelitian Afifuddin dkk pada penelitian selanjutnya dengan judul "Penerapan Metode Fuzzy Untuk Monitoring Penggunaan Air Rumah Tangga Berbasis Arduino”. Tujuan Penelitian adalah sistem monitoring air yang bisa melakukan pengisian tandon air secara otomatis, sehingga ketika kondisi level air dan penggunaan pada level tertentu maka akan membuka pengisian air ke tandon dengan cara otomatis, dengan memanfaatkan jarak pada sensor ultrasonik dan sensor debit air untuk mengontrol Arduino. Ketika data dari pembacaan pada sensor debit air akan mengirim ke website dengan menerapkan prinsip IoT. (Afifuddin, 2019)

Menurut penelitian Abidin dkk pada penelitian selanjutnya dengan judul "Rancang Bangun Sistem Monitoring Dan Controlling Pintu Air Dam Berbasis Arduino Menggunakan Implementasi Internet of Things". Tujuan penelitian adalah sistem otomatis pintu air bendungan merupakan alat yang di kembangkan pada bendungan sehingga ketika kondisi level tertentu pada air maka ketinggian tertentu pada pintu air ini dapat melakukan buka secara otomatis dengan cara memanfaatkan penggunaan sensor ultrasonic pada jaraknya dan kontrol arduino. Dalam hal ini data yang diperoleh akan masing-masing pada sensor akan dikirimkan ke website dengan menggunakan implementasi internet of thing (IoT). (Abidin, 2018)

Menurut penelitian Irvawansyah dkk pada penelitian selanjutnya dengan judul "Prototype Sistem Monitoring dan Pengontrolan Level Tangki Air Berbasis SCADA". Tujuan penelitian adalah sistem pengontrolan level air menggunakan sensor ultrasonik dan di tampilan pada laptop. Dari hasil pengujian ini menunjukkan bahwa dapat berjalan dengan baik dan disesuai dengan yang diinginkan, Di mana pada water pump apabila level ketinggian air pada tandon $10 \mathrm{~cm}$. apabila akan dihentikan secara otomatis maka ketinggian level air dalam tandon mencapai $70 \mathrm{~cm}$. (Irvawansyah, 2018)

\subsection{Dasar Teori}

\subsubsection{Pengertian Internet of Things}

Internet of Things atau biasa disingkat dengan Iot adalah konsep komputasi tentang objek sehari-hari yang terhubung ke jaringan internet dan mampu mengidentifikasi ke perangkat lain dengan benar. Penggunaan IoT dapat di terapkan ke berbagai hal antara lain adalah pada bidang pengawasan, pengontrollan dan sebagainya yang dapat saling bertukar data. Perkembangan IoT dapat di lihat dari tingkat konvergensi teknologi nirkabel, microelectromechanical (MEMS), internet, dan QR (Quick Responses) Code. (Efendi, 2018)

\subsubsection{NodeMCU ESP8266}

NodeMcu merupakan sebuah platform Iot yang memiliki sifat opensource atau dapat di ubah. NodeMcu ini terdiri dari perangkat keras dengan system On Chip ESP8266. Pengertian NodeMcu sebenarnya mengacu pada firmware yang digunakan pada peragkat keras yang digunakan development kit NodeMCU bisa dianalogikan sebagai boardnya pada ESP8266. Berikut spesifikasi dari alat tersebut Microcontroller Tensilica 32 bit, Flash Memory 4 $\mathrm{KB}$, Tegangan Operasi 3.3 V, Tegangan Input $7-12$ V, Digital I/O 16, Analog Input 1 (10 Bit), Interface UART: 1 , Interface SPI : 1 dan Interface I2C : 1 . (Bere, 2021)

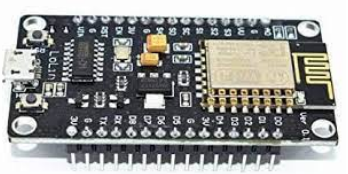

Gambar 1. NodeMCU ESP8266

\subsubsection{Limit Switch}

Modul Limit switch adalah jenis saklar yang dilengkapi dengan katup tombol yang berfungsi menggantikan tombol om dan of. Prinsip kerja limit switch adalah sama seperti saklar Push ON yaitu akan 
terhubung jika pada katupnya ditekan pada batas penekanan tertentu maka ditentukan dan akan memutus saat katup tidak ditekan. Limit switch juga termasuk pada kategori sensor mekanis yaitu sensor yang memberikan perubahan elektrik saat terjadi perubahan mekanik pada sensor yang digunakan. Saklar digunakan untuk mengetahui posisi sebuah batasan yang berhubungan dengan piston, silinder, rotor, pergerakan tempat mesin, dan lain-lain agar peralatan tersebut dapat terkontrol. (Nasir, 2018)

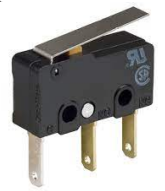

Gambar 2. Limit Swich

\subsubsection{Relay}

Relay adalah Saklar (Switch) yang dioperasikan secara listrik dan komponen listrik ini dioperasikan sebagai saklar. Relay yang digunakan pada penelitian ini adalah relay singgel channel. Komponen elektronika ini digunakan untuk menghubung dan matikan peralatan listrik yang bertegangan AC $220 \mathrm{~V}$. Relay singgel channel mempunya fungsi yang sama. Hanya saja perbedaan terletak pada kebutuhan masing-masing pada kebutuhan. Berikut spesifikasi dari alat tersebut seperti pin In, Ground, VCC 5V, Output 5v, Input Adaptor 5V dan Ground. (Andrianto, 2019)

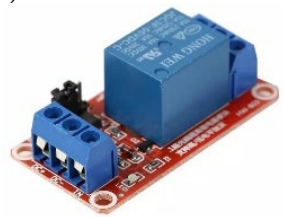

Gambar 3. Relay

\subsubsection{Buzzer}

Buzzer(speaker) merupakan sebuah modul komponen elektronik seperti transduser, yang cara bekerjanya dengan cara mengubah sinyal elektrik menjadi gelombang suara seperti berbunyi beep-beep pada perangkat elektronik, maka itu adalah suara buzzer. Berikut spesifikasi dari alat tersebut seperti Pin Digital dan Ground. (Ramady, 2020)

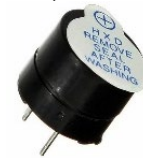

Gambar 4. Buzzer

\subsubsection{Led RGB}

LED RGB adalah sebuah LED yang dapat mengeluarkan cahaya warna red(merah), green(hijau), dan blue. LED adalah lampu LED yang bisa memancarkan cahaya 3 warna cahaya dalam satu unitLed saja secara bergantian, dinamakan LED RGB adalah karena singkatan dari 3 warna dalam bahasa Inggris yaitu $\mathrm{R}=\mathrm{Red}, \mathrm{G}=$ Green dan $\mathrm{B}=$ Blue. Cahaya yang dihasilkan oleh RGB LED sangat bagus sekali, karena cahaya tersebut dapat memancarkan secara bergantian tanpa menggunakan rangkaian elektronik tambahan. Diameter LED 5mm, 2.25 - 3V max, 20mA, Temperatur -30C $\sim$ + 85C. Berikut spesifikasi dari alat tersebut berwarna Red, Blue, Green dan Catoda. (Supegina, 2014)

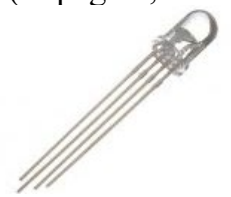

Gambar 5. Led RGB

\subsubsection{Water Pump}

Pompa air atau water pump adalah mesin atau peralatan mekanis yang salah satu komponen penting pada sistem sirkulasi air. Komponen tersebut berfungsi untuk mengalirkan air ke media sirkulasi air pada pendingin dari mesin ke bagian radiator bertujuan untuk mencegah terjadinya overheat. Berikut spesifikasi dari alat tersebut Tegangan 5V dan Ground. (Putra, 2018)

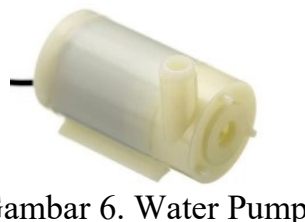

\subsubsection{Sensor Ultrasonic}

Sensor ultrasonik adalah alat yang berfungsi untuk mengubah besaran fisis atau bunyi menjadi besaranlistrik dan sebaliknya. Pada Sensor ini bekerja berdasarkan pantulan pada gelombang suara dan menafsirkan jarak sesuatu objek (benda) dengan frekuensi tertentu sehingga menghasilkan nilai. Sensor ini dapat bekerja dengan memanfaatkan gelombang ultrasonic. Berikut spesifikasi dari alat tersebut Tegangan 5V, Ground, Trig dan Echo. (Irvawansyah, 2018)

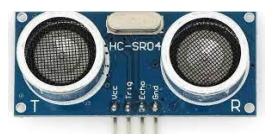

Gambar 7. Sensor Ultrasonic

\subsubsection{Arduino}

Arduino adalah sebuah board minimum system mikrokontroler yang bisa open source. Didalam rangkaian board arduino terdapat mikrokontroler AVR seri ATMega 328 yang merupakan produk dari Atmel. Untuk bahasa pemrograman pada arduino menggunakan bahasa $\mathrm{C}$ yang sudah disederhanakan syntax bahasa pemrogramannya sehingga mempermudah kita dalam mempelajari dan mendalami mikrokontroller. (Putra, 2018) 


\subsubsection{Monitoring}

Monitoring adalah sebuah teknologi yang menerapkan system iot untuk menampilkan pada layar monitor. Fungsi monitoring bertujuan untuk mempermudah dalam melakukan pemantau perubahan, yang focus pada proses dan keluaran. Monitoring melibatkan perhitungan atas apa yang kita lakukan. Monitoring melibatkan pengamatan atas kualitas dari layanan yang kita berian.

\subsubsection{Alat Minuman}

Alat tersebut merupakan alat yang di fungsikan untuk mengisikan minuman dengan cara otomatis setelah itu pada air galon di lakukan monitoring dan notifikasi untuk menjaga ketersediaan air galon di gedung dan perkantoran agar tetap terjaga untuk memudahkan dalam pengawasan.

\section{METODE PENELITIAN}

\subsection{Blok Diagram Sistem}

Sistem Minuman dan monitoring air galon mempunyai Sensor seperti sensor ultrasonic. System ini dikendalikan otomatis dan merupakan suatu trobosan atau penelitian yang dapat mempermudah pengawasan air galon minuman dan menghindari kehabisan air lalu di monitoring air galon agar terkontrol penggantian galonya. Beberapa yang di gunakan adalah hardware Sensor Ultrasonik, buzzer, Led RGB, ESP8266 node mcu, pompa dan Relay Setelah seluruh sensor melakukan pembacaan, mikrokontroller ESP Node MCU membuat pembacaan dari sensor ultrasonic untuk mengirimkan notifikasi level ketinggian air galon yang di pakai dan akan di tampilkan di website. Berikut penjelasan mengenai perancangan hardware dari sistem.

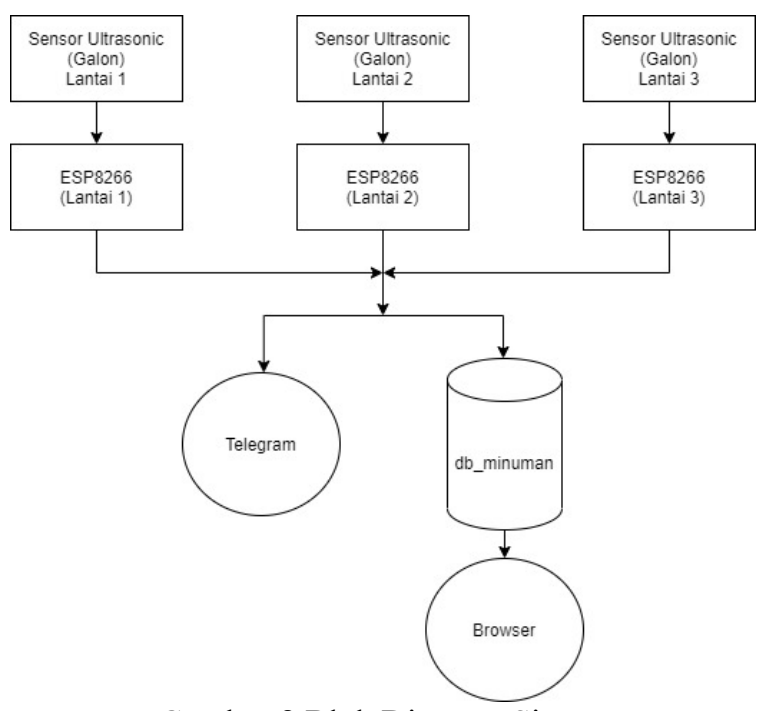

Gambar 8 Blok Diagram Sistem

\subsection{Use Case Diagram}

Use Case merupakan Suatu interaksi antara admin dan client dengan system yang akan di buat. Diagram ini digunakan untuk mencari fungsi apa saja yang ada dalam system sebuah fungsi yang kita buat seperti dibawah ini.

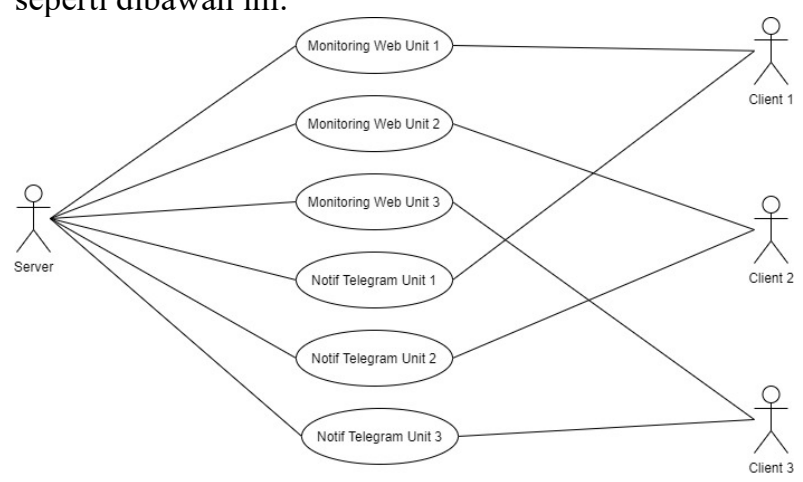

Gambar 9 Diagram Use Case

\subsection{Flowchart Sistem}

Pertama sensor ultrasonic apakah dapat mendeteksi ketinggian air? Jka bisa maka akan memonitoring ketinggian air galon ke website, jika tidak maka akan mengirimkan notif melalui telegram. Setelah itu data dari sensor ultrasonic di kirim melalui ESP8266 kemudian di kirim ke data base dengan nama db_minuman. Setelah itu data di tampilkan data dari sensor tersimpan ke database website dengan bantuan ESP8266 agar datanya akurat dan selanjutnya data akan muncul ke layar website.

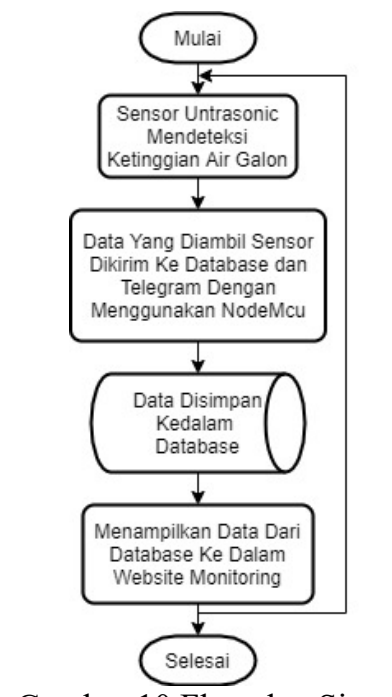

Gambar 10 Flowchat Sistem

\subsection{Flowchart Alat}

Pertama sensor ultranonic apakah sensor mendeteksi apakah masih ada air apa tidak? Jika ya maka led Hijau dan berjalan. Jika tidak maka led merah hidup dan buzzer berbunyi. Kemudian pada limit Switch apakah on apa off, jika on maka pompa hidup dan led hijau hidup, jika off maka pompa tidak hidup, kemudian lampu led hijau mati, lampu led merah hidup dan buzzer akan berbunyi Ketika pengisian selesai. Setelah itu data galon dari ultrasonic di kirim melalui ESP8266 kemudian di kirim ke data base dengan nama db_minuman. Setelah itu data di tampilkan data dari ultrasonic tersimpan ke database website dengan bantuan ESP 
8266. Kemudian notifikasi sisa air gallon habis akan mengirim notofikasi ke telegram dan untuk sisa air berapa persen selanjutnya data akan muncul ke layar website yang saya buat.

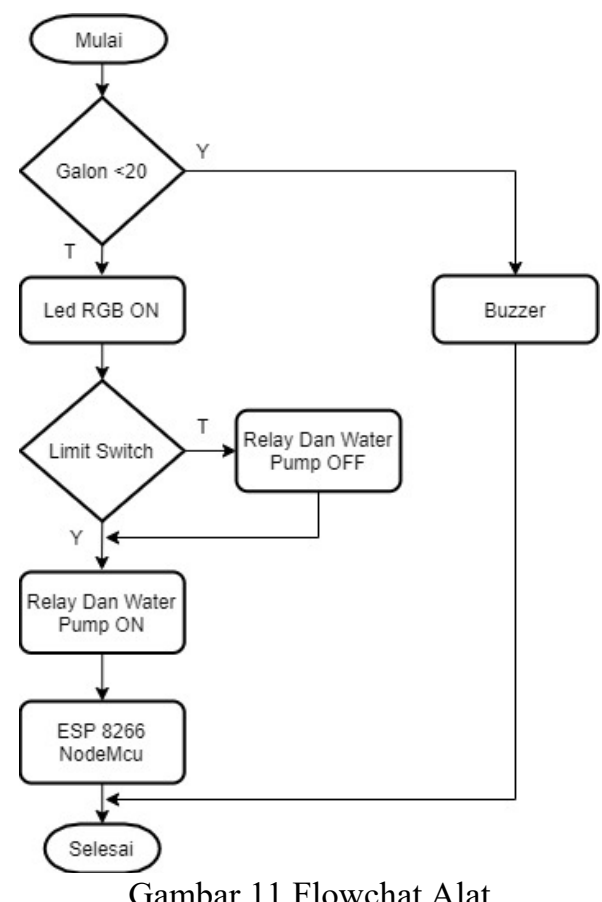

\section{HASIL DAN PEMBAHASAN}

Pada bab ini akan ditunjukkan hasil pengujian dan pembahasan proses yang sudah dilakukan.

\subsection{Pengujian Sistem Monitoring}

Rancang bangun prototipe merupakan rancangan dari sistem yang dibuat yaitu Sistem pengisian minuman dan monitoring air galon monitoring tingkat level air dapat dilihat pada Gambar 12

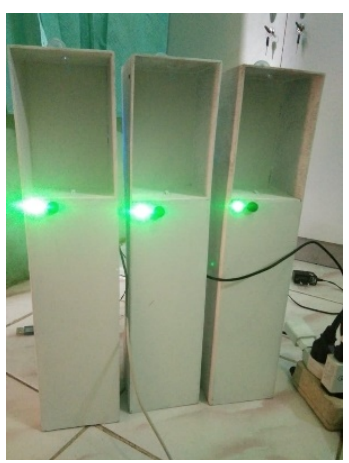

Gambar 12 Prototipe

\subsection{Halaman Telegram}

Halaman telegram. User melakukan cek ketinggian air dengan cara Cek galon unit 1, Cek galon unit 2 dan Cek galon unit 3 untuk menampilkan tingkat level air.

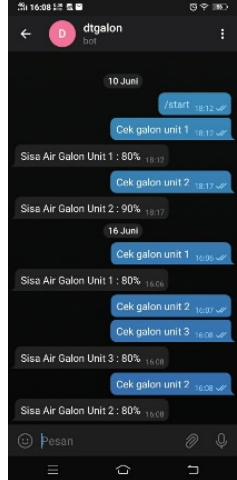

Gambar 13 Halaman Telegram

Tabel 1 Tabel telegram

\begin{tabular}{|c|c|c|c|}
\hline $\begin{array}{l}\text { Aktifitas } \\
\text { Pengujian }\end{array}$ & $\begin{array}{c}\text { Realisasi yang di } \\
\text { harapkan }\end{array}$ & $\begin{array}{c}\text { Hasil } \\
\text { Pengujian }\end{array}$ & Kesimpulan \\
\hline $\begin{array}{l}\text { notifikasi } \\
\text { pada unit } 1\end{array}$ & $\begin{array}{l}\text { Mampu } \\
\text { mengirimkan } \\
\text { notifikasi ketika } \\
\text { air } 0 \% \text { pada unit } \\
1\end{array}$ & $\begin{array}{l}\text { Muncul } \\
\text { notifikasi } \\
\text { Segera } \\
\text { Ganti Galon } \\
\text { Unit } 1 \text {, } \\
\text { Habis : } 0 \%\end{array}$ & $\begin{array}{l}\text { [ ] ditolak } \\
{[\mathrm{x}] \text { diterima }}\end{array}$ \\
\hline $\begin{array}{l}\text { notifikasi } \\
\text { pada unit } 2\end{array}$ & $\begin{array}{l}\text { Mampu } \\
\text { mengirimkan } \\
\text { notifikasi ketika } \\
\text { air } 0 \% \text { pada unit } \\
2\end{array}$ & $\begin{array}{l}\text { Muncul } \\
\text { notifikasi } \\
\text { Segera } \\
\text { Ganti Galon } \\
\text { Unit 2, } \\
\text { Habis : } 0 \%\end{array}$ & $\begin{array}{l}\text { [ ] ditolak } \\
{[\mathrm{x}] \text { diterima }}\end{array}$ \\
\hline $\begin{array}{l}\text { notifikasi } \\
\text { pada unit } 3\end{array}$ & $\begin{array}{l}\text { Mampu } \\
\text { mengirimkan } \\
\text { notifikasi ketika } \\
\text { air } 0 \% \text { pada unit } \\
3\end{array}$ & $\begin{array}{l}\text { Muncul } \\
\text { notifikasi } \\
\text { Segera } \\
\text { Ganti Galon } \\
\text { Unit 3, } \\
\text { Habis : } 0 \%\end{array}$ & $\begin{array}{l}\text { [ ] ditolak } \\
{[\mathrm{x}] \text { diterima }}\end{array}$ \\
\hline $\begin{array}{l}\text { notifikasi } \\
\text { pada dtgalon }\end{array}$ & $\begin{array}{l}\text { Mampu } \\
\text { mengirimkan } \\
\text { notifikasi ketika } \\
\text { air } 0 \% \text { pada unit } \\
1,2 \text { dan } 3\end{array}$ & $\begin{array}{l}\text { Muncul } \\
\text { notifikasi } \\
\text { Segera } \\
\text { Ganti Galon } \\
\text { Unit } 1,2 \text { dan } \\
3 \text {, Habis : } \\
0 \%\end{array}$ & $\begin{array}{l}\text { [ ] ditolak } \\
{[\mathrm{x}] \text { diterima }}\end{array}$ \\
\hline
\end{tabular}

Pada Gambar 13 merupakan halaman telegram. User melakukan cek ketinggian air dengan cara Cek galon unit 1, Cek galon unit 2 dan Cek galon unit 3 untuk menampilkan tingkat level air dimana sebagai indikator buat notif dan cek ketinggian. Pada dtgalon sebagai pusat dan dapat memonitoring semua unit pada unit1, unit 2 dan unit 3. Pada dtunit1 hanya dapat memonitoring pada unit 1 saja. Pada dtunit2 hanya dapat memonitoring pada unit 2 saja. Pada dtunit3 hanya dapat memonitoring pada unit 3 saja. jika air galon levelnya $0 \%$ maka akan mengirimkan notif ke ke semua unit pada dtgalon. Untuk dtunit 1 hanya dapat notif pada unit 1 saja ketika air galon $0 \%$. Sementara pada dtunit 2 hanya dapat notif pada unit 2 saja ketika air galon $0 \%$. Dan Untuk dtunit 3 hanya dapat notif pada unit 3 saja ketika air galon $0 \%$. Data yang di ambil melalui program esp 8266 node mcu.

\subsection{Tampilan Halaman Home Website}

Tampilan dari halaman dashboard pada website yang dapat dilihat pada gambar 14. merupakan 
gambar halaman dasboard website dimana berfungsi untuk menampilkan data ketinggian air secara realtime.

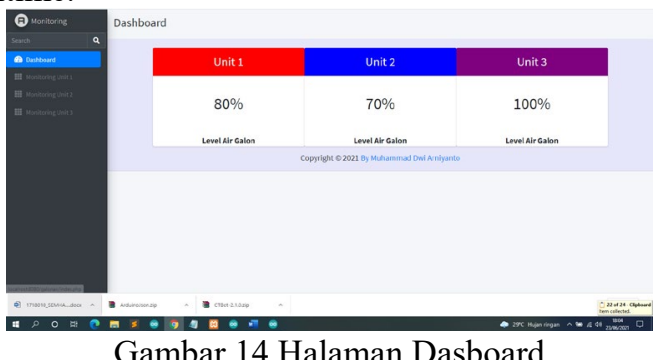

Tabel 2 Tabel home

\begin{tabular}{|l|l|l|l|}
\hline \multicolumn{1}{|c|}{$\begin{array}{c}\text { Aktifitas } \\
\text { Pengujian }\end{array}$} & $\begin{array}{c}\text { Realisasi } \\
\text { yang di } \\
\text { harapkan }\end{array}$ & \multicolumn{1}{|c|}{$\begin{array}{c}\text { Hasil } \\
\text { Pengujian }\end{array}$} & Kesimpulan \\
\hline $\begin{array}{l}\text { masuk ke } \\
\text { halaman } \\
\text { unit 1 }\end{array}$ & $\begin{array}{l}\text { Terhubung } \\
\text { ke menu } \\
\text { monitoring } \\
1\end{array}$ & $\begin{array}{l}\text { Muncul } \\
\text { berapa persen } \\
\text { prosentasenya }\end{array}$ & $\begin{array}{l}\text { [ ] ditolak } \\
\text { [x] diterima }\end{array}$ \\
\hline $\begin{array}{l}\text { masuk ke } \\
\text { halaman } \\
\text { unit 2 }\end{array}$ & $\begin{array}{l}\text { Terhubung } \\
\text { ke menu } \\
\text { monitoring } \\
2\end{array}$ & $\begin{array}{l}\text { Muncul } \\
\text { berapa persen } \\
\text { prosentasenya }\end{array}$ & {$[\mathrm{x}$ ] diterima } \\
\hline $\begin{array}{l}\text { masuk ke } \\
\text { halaman } \\
\text { unit 3 }\end{array}$ & $\begin{array}{l}\text { Terhubung } \\
\text { ke menu } \\
\text { monitoring } \\
3\end{array}$ & $\begin{array}{l}\text { Muncul } \\
\text { berapa persen } \\
\text { prosentasenya }\end{array}$ & {$[\mathrm{x}$ ] diterima } \\
\hline $\begin{array}{l}\text { Halaman } \\
\text { Tampilan } \\
\text { halaman } \\
\text { dashboard }\end{array}$ & $\begin{array}{l}\text { Terhubung } \\
\text { sesuai } \\
\text { tmpilan } \\
\text { unit 1, unit } \\
2 \text { dan unit } \\
3\end{array}$ & $\begin{array}{l}\text { Mampu } \\
\text { mengirim data } \\
\text { secara real } \\
\text { time pada unit } \\
1, \text { unit 2 dan } \\
\text { unit 3 }\end{array}$ & {$[\mathrm{x}$ ] diterima } \\
\hline
\end{tabular}

Pada Gambar 14 merupakan gambar halaman dasboard website dimana berfungsi untuk menampilkan data ketinggian air secara realtime. Pada halaman dashboard website sebagai pusat dan dapat memonitoring semua unit pada unit1, unit 2 dan unit 3 secara real time. Pada halaman tersebut mengambil data melalui program esp 8266 node mcu di teruskan ke kirimdata.php untuk di masukkan ke data base db_minuman. Setelah itu pada cekjarak.php digunakan untuk masukkan pada table tbsensor digunakan untuk unit 1 pada website. Pada table tbsensordua digunakan untuk unit 2 pada webite. Dan pada table tbsensortiga di gunakan pada unit 3 sebagai monitoring pada website.

\subsection{Tampilan Halaman Client Website}

Merupakan tampilan dari halaman Client website yang dapat dilihat pada gambar 15 . merupakan gambar halaman Monitoring Unit 1,2 dan 3 website dimana berfungsi untuk button dan menampilkan data ketinggian air secara real time.

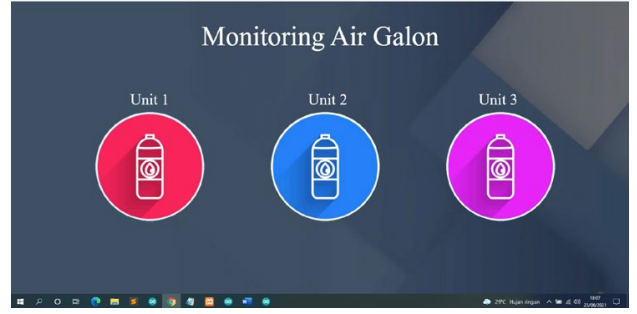

Gambar 15 Halaman Client

Tabel 3 Tabel client

\begin{tabular}{|c|c|c|c|}
\hline $\begin{array}{c}\text { Aktifitas } \\
\text { Pengujian }\end{array}$ & $\begin{array}{l}\text { Realisasi } \\
\text { yang di } \\
\text { harapkan }\end{array}$ & $\begin{array}{c}\text { Hasil } \\
\text { Pengujian }\end{array}$ & Kesimpulan \\
\hline $\begin{array}{l}\text { masuk ke } \\
\text { halaman } \\
\text { unit } 1\end{array}$ & $\begin{array}{l}\text { Terhubung } \\
\text { dengan rest } \\
\text { server unit } 1\end{array}$ & $\begin{array}{l}\text { Muncul } \\
\text { berapa persen } \\
\text { prosentasenya }\end{array}$ & $\begin{array}{l}\text { [ ] ditolak } \\
\text { [x] diterima }\end{array}$ \\
\hline $\begin{array}{l}\text { masuk ke } \\
\text { halaman } \\
\text { unit } 2\end{array}$ & $\begin{array}{l}\text { Terhubung } \\
\text { dengan rest } \\
\text { server unit } 2 \\
\end{array}$ & $\begin{array}{l}\text { Muncul } \\
\text { berapa persen } \\
\text { prosentasenya }\end{array}$ & $\begin{array}{l}\text { [ ] ditolak } \\
\text { [x] diterima }\end{array}$ \\
\hline $\begin{array}{l}\text { masuk ke } \\
\text { halaman } \\
\text { unit } 3\end{array}$ & $\begin{array}{l}\text { Terhubung } \\
\text { dengan rest } \\
\text { server unit } 3\end{array}$ & $\begin{array}{l}\text { Muncul } \\
\text { berapa persen } \\
\text { prosentasenya }\end{array}$ & $\begin{array}{l}\text { [ ] ditolak } \\
\text { [x] diterima }\end{array}$ \\
\hline $\begin{array}{l}\text { Halaman } \\
\text { Tampilan } \\
\text { Awal } \\
\text { Client }\end{array}$ & $\begin{array}{l}\text { Terhubung } \\
\text { sesuai } \\
\text { dengan } \\
\text { button unit } \\
1 \text {, unit } 2 \text { dan } \\
\text { unit } 3 \\
\end{array}$ & $\begin{array}{l}\text { Mampu } \\
\text { masuk } \\
\text { kehalaman } \\
\text { yang dituju ke } \\
\text { unit } 1 \text {, unit } 2 \\
\text { dan unit } 3 \\
\end{array}$ & $\begin{array}{l}\text { [ ] ditolak } \\
{[\mathrm{x}] \text { diterima }}\end{array}$ \\
\hline
\end{tabular}

Pada Gambar 15 merupakan gambar halaman Monitoring Unit 1,2 dan 3 website dimana berfungsi untuk button dan menampilkan data ketinggian air secara real time. Pada halaman client website digunakan sebagai memonitoring unit pada unit1, unit 2 dan unit 3 secara real time dan tompol button pada unit 1, unit 2 dan unit 3 dapat di tekan tombol buttonnya agar bisa masuk mada halaman sesuai yang di inginkan. Pada halaman client website sebagai pusat dan dapat memonitoring semua unit pada unit1, unit 2 dan unit 3 secara real time. Pada halaman client tersebut mengambil data melalui halaman backend di teruskan ke halaman client untuk di tampilkan pada halaman website. Pada tampilan halanan terdapat 3 tombol button di gunakan untuk masuk pada pada halaman pada unit 1 untuk button unit 1, pada halaman unit 2 untuk button unit 2 agar dapat masuk ke halaman unit 2, dan pada halaman unit 3 untuk button unit 3 untuk dapat masuk pada halaman unit 3 yang datanya di ambil melalui server yang telah di buat.

\subsection{Pengujian ESP 8266 Node MCU}

Pada penelitian ini dilakukan pengujian pada modul ESP8266 dimana seperti pada gambar 15

\section{$\mathrm{COM} 3$}

।

Mencari Jaringan ....

. Connected

Koneksi Berhasil

Gambar 15. Tampilan pengujian ESP8266 
Tabel 4. Tabel Pengujian ESP NODE MCU

\begin{tabular}{|c|c|c|c|c|}
\hline $\begin{array}{c}\text { N } \\
\text { o }\end{array}$ & $\begin{array}{c}\text { Terhubu } \\
\text { n Ke } \\
\text { AP }\end{array}$ & $\begin{array}{c}\text { Terhubu } \\
\text { ng Ke } \\
\text { Server }\end{array}$ & $\begin{array}{c}\text { Data } \\
\text { Sucses } \\
\text { Di Kirim }\end{array}$ & $\begin{array}{c}\text { Delay } \\
\text { (detik } \\
\text { ) }\end{array}$ \\
\hline 1 & YA & YA & YA & 7 \\
\hline 2 & YA & YA & YA & 7 \\
\hline 3 & YA & YA & YA & 7 \\
\hline 4 & YA & YA & YA & 7 \\
\hline 5 & TIDAK & TIDAK & TIDAK & 7 \\
\hline 6 & YA & YA & YA & 7 \\
\hline
\end{tabular}

Dari pengujian ESP 8266 Node MCU ini memiliki ke tingkat terhubung sangat besar, sedangkan untuk tingkat kegagalan saat terkoneksi cukup kecil.

\subsection{Pengujian Sensor Ultrasonic}

Pada penelitian ini juga dilakukan pengujian pada sensor Ultrasonic seperti pada gambar 16

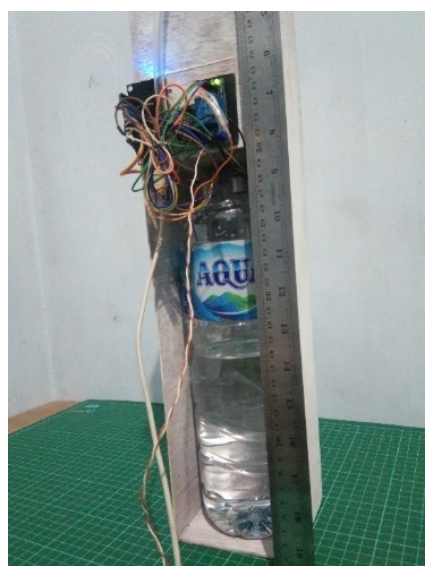

Gambar 16. Pengujian Sensor ultrasonic

Tabel 5. Tabel Pengujian Ultrasonic

\begin{tabular}{|c|c|c|c|}
\hline No & Sensor & $\begin{array}{c}\text { Nilai } \\
\text { Ultrasonic }\end{array}$ & $\begin{array}{c}\text { Nilai } \\
\text { Persen }\end{array}$ \\
\hline 1 & Ultrasonic & $20-22$ & $10 \%$ \\
\hline 2 & Ultrasonic & $19-20$ & $20 \%$ \\
\hline 3 & Ultrasonic & $17-19$ & $30 \%$ \\
\hline 4 & Ultrasonic & $15-17$ & $40 \%$ \\
\hline 5 & Ultrasonic & $13-15$ & $50 \%$ \\
\hline 6 & Ultrasonic & $11-13$ & $60 \%$ \\
\hline 7 & Ultrasonic & $9-11$ & $70 \%$ \\
\hline 8 & Ultrasonic & $7-9$ & $80 \%$ \\
\hline 9 & Ultrasonic & $5-7$ & $90 \%$ \\
\hline 10 & Ultrasonic & $0-5$ & $100 \%$ \\
\hline
\end{tabular}

Dari pengujian sensor ultrasonic tersebut merupakan nilai yang dibandingkan Melakukan Percobaan hasil nilai pada sensor ultrasonic untuk melakukan konfigurasi nilai agar tepat. Sehingga nilai tersebut pada sensor ultrasonic tidak lompat-lompat sehingga dapat melakukan pengontrollan secara real time.

\subsection{Pengujian Limit Switch}

Pada penelitian ini juga dilakukan pengujian pada Percobaan Saklar Limit Switch Dan Lampu LED RGB.seperti pada gambar 17

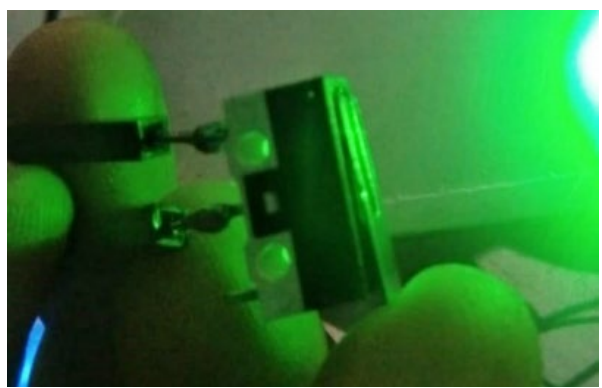

Gambar 17. Pengujian limit switch dan led

Tabel 6. Tabel Pengujian Limit Swich

\begin{tabular}{|c|c|c|c|}
\hline No & $\begin{array}{c}\text { Saklar Limit } \\
\text { Swith }\end{array}$ & $\begin{array}{c}\text { Delay } \\
\text { program }\end{array}$ & $\begin{array}{c}\text { Delay } \\
\text { alat }\end{array}$ \\
\hline 1 & On unit 1 & 1 detik & 6 detik \\
\hline 2 & Off unit 1 & 1 detik & 5 detik \\
\hline 3 & On unit 2 & 1 detik & 12 detik \\
\hline 4 & Off unit 2 & 1 detik & 7 detik \\
\hline 5 & On unit 3 & 1 detik & 10 detik \\
\hline 6 & Off unit 3 & 1 detik & 9 detik \\
\hline
\end{tabular}

Dari Hasil pengujian limit switch dan led bahwa keduanya dapat berjalan dengan lancer dan tidak delay sama sekali. Saklar ini menggunakan pin digital 0 dan 1 jika 0 off jika on maka 1 .

\subsection{Pengujian Software}

Berikut merupakan Pengujian software pada penelitian ini dengan dilakukanya menguji website pada web browser yang berfungsi untuk mengetahui apakai website ini dapat menampilkan keseluruhan informasi yang ada. Berikut merupakan tabel pengujian fungsional.

Tabel 7. Tabel Pengujian browser

\begin{tabular}{|l|l|c|c|}
\hline No & Aspek Pengujian & Chrome & Edge \\
\hline 1 & Halaman Back End & $\checkmark$ & $\checkmark$ \\
\hline 2 & Halaman Unit 1 & $\checkmark$ & $\checkmark$ \\
\hline 3 & Halaman Unit 2 & $\checkmark$ & $\checkmark$ \\
\hline 4 & Halaman Unit 3 & $\checkmark$ & $\checkmark$ \\
\hline 5 & Halaman FrontEnd & $\checkmark$ & $\checkmark$ \\
\hline 6 & Button Halaman Unit 1 & $\checkmark$ & $\checkmark$ \\
\hline 7 & Button Halaman Unit 2 & $\checkmark$ & $\checkmark$ \\
\hline 8 & Button Halaman Unit 3 & $\checkmark$ & $\checkmark$ \\
\hline
\end{tabular}

Dari tabel pengujian yang ada diatas, dapat disimpulkan bahwa monitoring melalui website dapat berfungsi dengan baik pada Web Browser seperti Microsoft Edge versi 91.0.864.54 (Official build) (64bit) dan Google Chrome Version 91.0.4472.106 (Official Build) (64-bit). 


\section{KESIMPULAN DAN SARAN}

\subsection{Kesimpulan}

Kesimpulan yang dapat diuraikan dari hasil pembuatan projek iot rancang bangun alat pengisian minuman dan monitoring berbasis iot yaitu:

1. Dapat Melakukan Monitoring Menggunakan Website Pada Air Galon Unit 1, Unit 2 Dan Unit 3 Agar dapat di control tingkat ketinggian air galon dan dijalankan dengan baik pada browser web.

2. Berdasarkan hasil pengujian pada notifikasi pada unit 1, unit 2 dan unit 3 dapat memudahkan untuk melakukan pengawasan melalui telegram.

3. Berdasarkan hasil pengujian aplikasi dengan menggunakan 2 browser yang berbeda, semua tampilan dan fungsi aplikasi dapat berjalan $100 \%$ pada 2 browser yaitu, Microsoft Edge versi 91.0.864.54 (Official build) (64-bit) dan Google Chrome Version 91.0.4472.106 (Official Build) (64bit).

\subsection{Saran}

Adapun saran yang diberikan untuk penelitian selanjutnya antara lain:

1. Penelitian selanjutnya dapat di kembangkan dalam penelitian selanjutnya agar dapat mungkinkan untuk penambahan fitur lain seperti notifikasi berupa sms dan telefon .

2. Penelitian selanjutnya dapat di kembangkan pada tampilan website dan fitur lainya agar pengguna mudah dalam pengoprasianya.

\section{DAFTAR PUSTAKA}

[1] Anggara, A., Rahman, A. and Mufti, A., 2018. Rancang Bangun Sistem Pengatur Pengisian Air Galon Otomatis Berbasis Mikrokontroler ATmega328p. Jurnal Karya Ilmiah Teknik Elektro,

[2] Dewanto, E., Yoseph, J. and Rifâ, M., 2018. Tandon Air Otomatis Dengan Sistem Monitoring Melalui Android Berbasis Arduino Uno. AUTOCRACY: Jurnal Otomasi, Kendali, dan Aplikasi Industri, 5(01), pp.8-16.

[3] Putra, I.N., 2018. RANCANG BANGUN SISTEM MONITORING KOLAM RENANG BERBASIS WEB DENGAN IOT. JATI (Jurnal
Mahasiswa Teknik Informatika), 2(2), pp.116121.

[4] Bere, S., Mahmudi, A. and Sasmito, A.P., 2021. RANCANG BANGUN ALAT PEMBUKA DAN PENUTUP TONG SAMPAH OTOMATIS MENGGUNAKAN SENSOR JARAK BERBASIS ARDUINO. JATI (Jurnal Mahasiswa Teknik Informatika), 5(1), pp.357363

[5] Wagino, W. and Arafat, A., 2018. Monitoring Dan Pengisian Air Tandon Otomatis Berbasis Arduino. Technologia: Jurnal Ilmiah, 9(3), pp.192-196.

[6] Afifuddin, A.A., 2019. Penerapan Metode Fuzzy untuk Monitoring Penggunaan Air Rumah Tangga Berbasis Arduino. JATI (Jurnal Mahasiswa Teknik Informatika), 3(1), pp.31-38.

[7] Abidin, Z., 2018. Rancang Bangun Sistem Monitoring dan Controlling Pintu Air Dam Berbasis Arduino Menggunakan Implementasi Internet of Things. JATI (Jurnal Mahasiswa Teknik Informatika), 2(2), pp.282-289.

[8] Irvawansyah, A.A.R., 2018. Prototype Sistem Monitoring dan Pengontrolan Level Tangki Air Berbasis SCADA. Jurnal Teknologi Terapan. ISSN, pp.2549-1938.

[9] Nazir, M., Jamaluddin, J. and Muhaimin, M., 2018. RANCANG BANGUN SISTEM PENGAMAN PINTU RUMAH MENGGUNAKAN KODE PASSWORD DAN SMARTPHONE BERBASIS MIKROKONTROLLER. Jurnal TEKTRO, 1(1), pp.30-35.

[10] Ramady, G.D., Yusuf, H., Hidayat, R., Mahardika, A.G. and Lestari, N.S., 2020. Rancang Bangun Model Simulasi Sistem Pendeteksi Dan Pembuangan Asap Rokok Otomatis Berbasis Arduino. Jurnal Teknik Komputer, 6(2), pp.212-218.

[11] Supegina, F. and Imam, I., 2014. Pengaturan Lampu Taman LED RGB Berbasis Arduino yang Dilengkapi Solar Cell. SINERGI, 18(1), pp.9-14. 